\title{
Implication of prescriptions for nitrates: 7 year follow up of patients treated for angina in general practice
}

\author{
Karen W Clarke, David Gray, John R Hampton
}

\begin{abstract}
Objective-To determine the demand placed on local cardiological services by patients prescribed nitrates for ischaemic heart disease.

Design-A follow up study of a cohort of patients identified in 1985 .

Setting-Nottingham Health District.

Patients-Four hundred and ninety nine patients prescribed nitrates in 1985 for presumed ischaemic heart disease.

Main outcome measures-Referral to medical outpatients, admittance to hospital with chest pain, cardiological investigations, and mortality.

Results-Over the seven year period $26 \%$ of patients were admitted urgently with chest pain and $15 \%$ were referred to the medical outpatient department-a referral rate of $6 \%$ a year. $4 \%$ of patients had an exercise test and $6 \%$ a coronary angiogram. The death rate was $6 \%$ a year and a higher proportion died of cardiovascular causes than would be expected in the general population.

Conclusions-Prescription of nitrate is useful in the determination of the prevalence of ischaemic heart disease. Most patients with angina are still treated within the community, and the rate of specialist investigation remains low.
\end{abstract}

(Br Heart f 1994;71:38-40)

Ischaemic heart disease affects between $4 \cdot 8 \%^{1}$ and $7.9 \%{ }^{2}$ of middle aged men in the United Kingdom. This places a considerable demand on both inpatient and outpatient resources and caused in excess of 148000 deaths in England and Wales in $1990 .^{3}$ Recently the annual incidence of new cases of angina has been estimated to be in the region of 22000 for the United Kingdom. ${ }^{4}$

In allocating hospital and specialist resources it is important to know not only the prevalence of a condition, but also the demands of general practitioners for hospital referral and specialist investigation. The prevalence of angina in 1985 in Nottingham, based on an analysis of 6856 patients prescribed a long acting nitrate for angina by their general practitioner, was estimated to be $1.5 \% .^{5}$ Review of a random sample of 499 patients taking nitrates showed that few had been referred for further investigation. Although $64 \%$ had had an electrocardiogram, only $7 \%$ had had an exercise test, and $4 \%$ a coronary angiogram. Nineteen per cent of the patients had attended a hospital outpatient clinic and half of these had seen a cardiologist. In most cases, the diagnosis and management of angina was therefore based on the patient's history.

We followed up this sample of patients who had been prescribed long acting nitrates by the general practitioner for presumed angina to determine the demand placed on hospital and cardiology services in the subsequent 7 years, and to look at rates and causes of death.

\section{Patients and methods}

The patients identified in the 1985 study were followed up until 1992. To trace them various methods were used:

(a) The hospital computer system was searched and the case notes of those patients who had had any contact with the Nottingham hospitals were examined; for those patients not known to the hospitals or whose hospital records did not show a recent appointment, their records were examined in the general practitioner's surgery.

(b) The Family Health Services Authority was contacted to trace those patients who might have registered with a different general practitioner since the 1985 survey; the new general practitioner was approached and the record examined. The Family Health Services Authority also provided information on those patients who had died and a list of deceased patients whose medical records had been destroyed. They were also able to list people who had left Nottinghamshire.

(c) The Office of Population Censuses and Surveys provided information on deceased patients where this was not locally available.

Information was obtained on the number of and reason for any hospital admissions, and the investigations carried out. Hospital admissions were coded:

(a) Myocardial infarction: evolution of sequential ST segment changes and new pathological $Q$ waves on the electrocardiogram and a rise in serum cardiac enzymes to greater than twice the upper limit of normal.

(b) Probable myocardial infarction: either evolution of sequential ST segment changes and new pathological $Q$ waves on the electrocardiogram or a rise in cardiac enzymes to more than twice the upper limit of normal.

(c) Possible myocardial infarction: a history of chest pain with either electrocardiographic changes other than $Q$ waves or a rise in 
cardiac enzymes but to less than twice the upper limit of normal.

(d) Ischaemic heart disease: a history of a previous myocardial infarction with pathological $Q$ waves on the electrocardiogram recorded at admission but with no changes in subsequent electrocardiography or cardiac enzymes suggestive of a new event.

(e) Chest pain of unknown cause: admission and subsequent electrocardiograms and cardiac enzymes normal without objective evidence of a cause for symptoms other than myocardial ischaemia.

$(f)$ Not ischaemic heart disease: objective evidence of another cause for chest pain or admitted with something other than chest pain.

The last date that the patient was known to be alive was recorded as was the date and cause of death, coded as cardiovascular or non-cardiovascular if known.

\section{Results}

PATIENT DEMOGRAPHY

Of the original 499 patients in the 1985 study, $15(3 \%)$ had left Nottingham, there was insufficient original information to identify $36(7 \%)$ patients so an adequate search was impossible, and the Family Health Services Authority were unable to trace a further $23(4 \%)$ people. Detailed information was available on the remaining 425 patients.

The median (range) age of these patients in 1985 was 71 (33 to 95 ) and $75 \%$ were over $65 \cdot 246(58 \%)$ were men.

HOSPITAL ADMISSIONS

Of these 425 patients, $216(51 \%)$ were admitted to one of the Nottingham hospitals at some time since 1985 . One hundred and twelve patients had been admitted with chest pain suggestive of acute myocardial infarction and the rest had been admitted to a nonmedical speciality. Some patients were admitted on more than one occasion. There were a total of 193 admissions with chest pain, but of these only 28 had a diagnosis at discharge of definite myocardial infarction, 31 of probable myocardial infarction, 50 had a possible myocardial infarction, 41 ischaemic heart disease, and 43 chest pain of unknown cause. The total number of patients who have likely had a myocardial infarction is therefore 59 $(14 \%)$ - a rate of $2 \%$ per year.

REFERRAL TO HOSPITAL OUTPATIENTS

A further 65 (15\%) patients had been referred to a medical outpatient department with symptoms of chest pain. The total number of patients referred to the hospital since 1985 is therefore $177(42 \%)$.

INVESTIGATIONS PERFORMED

Altogether since $1985,180(42 \%)$ patients have had an electrocardiogram, $18(4 \%)$ an exercise electrocardiogram, and $26(6 \%)$ a coronary angiogram. None of the patients who had coronary angiograms before 1985 had been reinvestigated.

\section{CAUSE OF DEATH}

$166(39 \%)$ of the patients have died, of whom 54 have died of cardiovascular causes. In 56 patients the cause of death is unknown. Fifty five of the patients who died had had no contact with the hospital, and of these $16(29 \%)$ died of cardiovascular causes. Of the 112 patients admitted urgently with chest pain 57 have died, 27 of cardiovascular causes (figure).

\section{Discussion}

Most patients with suspected angina are treated by general practitioners without the assistance or knowledge of the hospital or cardiological specialist. ${ }^{5}$ General practitioners thus act as gate keepers, controlling access to cardiological services and treat at least 15 patients with angina for each one known to the hospital services. This has been likened to a "dam holding back water". ${ }^{6}$ The risk of the hospital services being overwhelmed is
Demographic details of patients. MI, myocardial infarction.

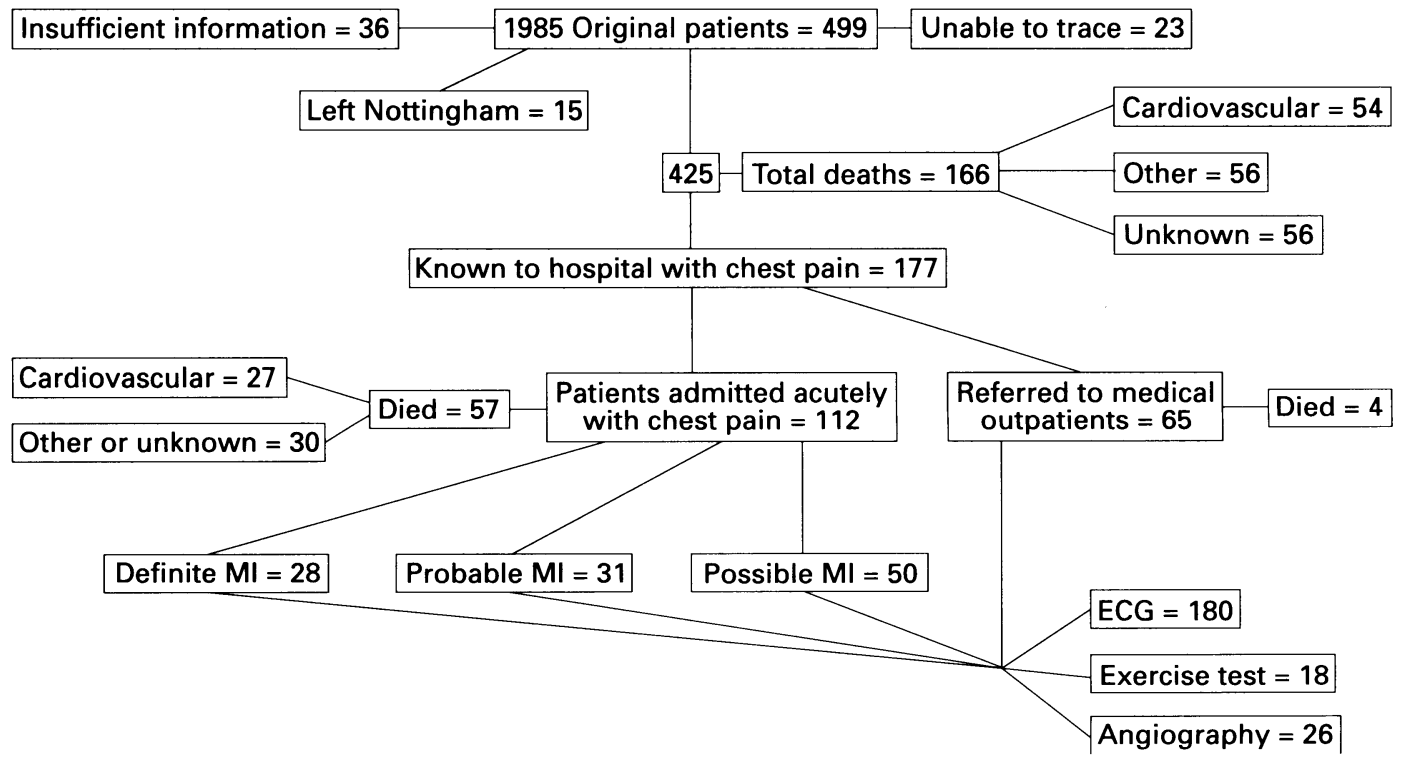


great should there be even a small change in referral patterns by general practitioners. Cardiology services could become overrun if patients with initially mild symptoms were subsequently thought to require detailed investigation.

Obviously the potential for gate keeping general practitioners to modify referral patterns still exists. This study has shown that $40 \%$ of the patients identified from nitrates prescribed 7 years previously by general practitioners have come to the attention of the hospital in the ensuing 7 years-a referral rate of $6 \%$ a year. More than half of the patients therefore continue to be cared for largely in the community. Of those who do come to the attention of the hospital, referral for specialist advice and further investigation is unusual and despite the number of patients in the community on nitrates, excessive demands on the hospital and specialist services have not been evident.

In the 7 years since they were first identified, $26 \%$ of the patients were admitted to hospital with chest pain, but few $(14 \%)$ have had a confirmed myocardial infarction. This compares with data from the Framingham study in which $25 \%$ of men with angina had a myocardial infarction within five years. ${ }^{7}$ The rate of investigation remains low. This may simply be because patients are not thought by their general practitioners to need further investigation (perhaps because their symptoms are not restrictive or because they do not have angina at all) and therefore are not referred to the hospital, or that on referral specialised cardiological investigation is then thought not to be necessary.

About $30 \%$ of patients were on more than one antianginal drug in 1985 , and therefore could be considered to have relatively severe disease. Referral to hospital was no more frequent in this group than in the rest of the patients; nor were they more likely to undergo coronary angiography.

Of the general population of England and Wales $16 \%$ is aged 65 and over, and the crude death rate for this group is $5.6 \%$. We would expect $30 \%$ of the deaths in this age group to be due to heart disease. ${ }^{3} \mathrm{~A}$ higher percentage of patients in the 1985 nitrate cohort were aged 65 and over. Of the 166 patients who have died only 12 were younger than 65 at the time of their death. The crude death rate in our patients was higher than that in the general population of similar age at $40 \%$, (about $6 \%$ a year) and where we have full information the cause of death has been given as cardiovascular disease in half.
Mortality in patients with medically treated angina has previously been reported as between $1.6 \%$ and $5 \%$ a year. ${ }^{7-11}$ As our patients have a comparable (or indeed higher death rate), it is reasonable to assume that the initial diagnosis of angina was correct, and therefore that nitrate prescriptions are a useful epidemiological tool in the determination of the prevalence of ischaemic heart disease. In view of this higher death rate in our patients, however, and the higher rate of death due to cardiovascular disease, we might speculate as to whether hospital referral and more aggressive specialist intervention would influence mortality in this group.

Angina is common and if general practitioners prescribe long acting nitrates for patients with symptoms of chest pain, the diagnosis of angina, based upon the history and a knowledge of cardiovascular risk factors, without benefit of investigations, is usually correct, ${ }^{5}$ and we have shown that a nitrate prescription does indeed mean that the patient has angina. There remains a large pool of patients in the community who are potential candidates for specialist referral and investigation; however, if referral habits of general practitioners remain as they are, the consequences for hospital and specialist services do not seem to be overwhelming.

We thank the Medical Records staff at the University and City Hospitals, the staff at the Family Health Services Association, and the general practitioners, without whose assistance this study would not have been possible.

$\mathrm{KC}$ is the Prophit-Rosser Fellow of the Royal College of Physicians.

1 Rose G, Reid DD, Hamilton PJS, McCartney P, Keen H, Jarrett RJ. Myocardial ischaemia, risk factors and death from coronary heart disease. Lancet 1977;i:105-9.

2 Shaper AG, Cook DG, Walker M, MacFarlane PW. Prevalence of ischaemic heart disease in middle aged Prevalence of ischaemic heart disease in
British men. Br Heart $\mathcal{7} 1984 ; 51: 595-605$

3 Office of Population Censuses and Surveys. Mortality statistics, England and Wales 1990. London: HMSO, 1991.

4 Gandhi MM, Lampe F, Wood DA. Incidence of stable angina pectoris [abstr]. Eur Heart $\mathcal{f}$ 1992;13:181. Poster 1069:181

5 Cannon PJ, Stockley IH, Connell PA, Garner ST, Hampton JR. Prevalence of angina as assessed by a survey of prescriptions for nitrates. Lancet 1988;i:979-81.

6 Hampton JR. In: Smith R. Rationing: the search for sunlight. Br Med F 1991;303:1561-2.

7 Kannel WB, Feinleib M. Natural history of angina pectoris in the Framingham study. Am $\mathcal{f}$ Cardiol 1972;29. 154-63.

8 Mock MB, Ringqvist I, Fisher LD, et al. Survival of medically treated patients in the Coronary Artery Surgery Study (CASS) registry. Circulation 1982;66:562-8.

9 European Coronary Surgery Study Group. Long-term results of prospective randomised study of coronary artery bypass surgery in stable angina pectoris. Lancet 1982;ii:1173-80.

10 Fry J. The natural history of angina in a general practice $\mathcal{J} R$ Coll Gen Pract 1976;26:643-6.

11 Harris PI, Harrell FE, Lee KL, Behar VS, Rosati RA Survival in medically treated coronary artery disease. Circulation 1979;60:1259-69. 